\title{
Large ovarian dermoid, a cause for fetal growth restriction and oligohydramnios: rare instance in literature
}

\author{
Anupma $^{1}$, Avir Sarkar ${ }^{2 *}$, Deepak Yadav ${ }^{1}$, Jagadish C. Sharma ${ }^{1}$
}

\begin{abstract}
${ }^{1}$ Department of Obstetrics and Gynecology, ESIC Medical College and Hosptal, Faridabad, Haryana, India
${ }^{2}$ Department of Obstetrics and Gynecology, All India Institute of Medical Sciences, Ansari Nagar, New Delhi, India
\end{abstract}

Received: 17 September 2021

Accepted: 08 October 2021

\section{*Correspondence:}

Dr. Avir Sarkar,

E-mail: avirsarkar93@gmail.com

Copyright: ( $)$ the author(s), publisher and licensee Medip Academy. This is an open-access article distributed under the terms of the Creative Commons Attribution Non-Commercial License, which permits unrestricted non-commercial use, distribution, and reproduction in any medium, provided the original work is properly cited.

\begin{abstract}
Ovarian dermoids mostly remain asymptomatic during pregnancy. Large dermoids may present with torsion, hemorrhage or rupture. However, a dermoid cyst causing fetal growth restriction (FGR) and oligohydramnios is a very rare entity. We report a case of a large ovarian dernoid $(15 \times 12 \mathrm{~cm})$ hampering intrauterine fetal growth. Due to the COVID-19 lockdown, patient was unable to get ultrasound examinations in early gestation, and thereby surgical intervention was not possible during the second trimester. As a result, this growing teratoma finally led to FGR by either exerting a pressure effect upon the uterus or by dwindling its blood supply.
\end{abstract}

Keywords: Dermoid cyst, Fetal growth restriction, Oligohydramnios, Teratoma

\section{INTRODUCTION}

Ovarian tumors are not common during pregnancy. They are present in $0.3 \%$ of pregnancies and are usually detected between 16-20 weeks of gestation. ${ }^{1}$ Dermoids, being the most common benign ovarian neoplasm in pregnancy, remain mostly asymptomatic. ${ }^{2}$ Majority are incidentally diagnosed during antenatal ultrasounds. Some become symptomatic when they present with acute pain and tenderness owing to torsion, hemorrhage or rupture. It is often advocated to remove adnexal masses more than $5 \mathrm{~cm}$ in diameter. Best time for surgical intervention is second trimester. We hereby report a case of a huge ovarian dermoid cyst which resulted in fetal growth restriction (FGR) and oligohydramnios, rarest of the complications to be ever noticed till date.

\section{CASE REPORT}

A 25-year-old second gravida with previous one caesarean delivery 3 years back, was referred to us at 34 weeks period of gestation (POG) due to a large complex cyst in left ovary. The cyst was unilocular, measuring $12.5 \times 13.7$ $\mathrm{cm}$, with mural components and multiple thin, echogenic bands with dot and dash pattern suggestive of a dermoid cyst (Figure 1). It was an asymptomatic cyst discovered incidentally during ultrasound examination at 32 weeks POG. Coming from a rural background, prolonged lockdown in the country due to the COVID-19 pandemic prevented her from getting an easy access to medical facility for ultrasounds during early antenatal period. Thus, there were no dating and anomaly scans till now.

During her first visit to our antenatal clinic at 34 weeks POG, her general condition was fair and vitals were stable. On per abdominal examination, fundal height was corresponding to 36 weeks size gravid uterus with a symphysio-fundal height of $35.8 \mathrm{~cm}$. However, a solidcystic mass could be vaguely appreciated towards the left flank. Fetus was in longitudinal lie, with cephalic presentation and fetal heart rate was around 140 beats per minute. An ultrasound conducted in our clinic the same day showed a single live intrauterine fetus corresponding to 30 weeks of gestation! It was in cephalic presentation. There were no gross structural abnormalities. Placenta was located in fundo-anterior segment of uterus with grade II 
maturity. Liquor was on the lower side with an amniotic fluid index (AFI) of $6.0 \mathrm{~cm}$. The estimated fetal weight was around $1.4 \mathrm{~kg}$. Umbilical artery Doppler studies were however normal with good diastolic flow. Fetal non stress tests (NST) were suggestive of a reassuring fetal status. There was no history of increased blood pressure records, no history suggestive of leaking per vaginum or recent fever, diarrhea and dehydration. Coming from a lowermiddle socio-economic class, her nutrition status was fairly good. She was not addicted to intake of alcohol, caffeine or smoking. On detailed history taking, records of first pregnancy showed that previous baby had a birth weight of $3.0 \mathrm{~kg}$.

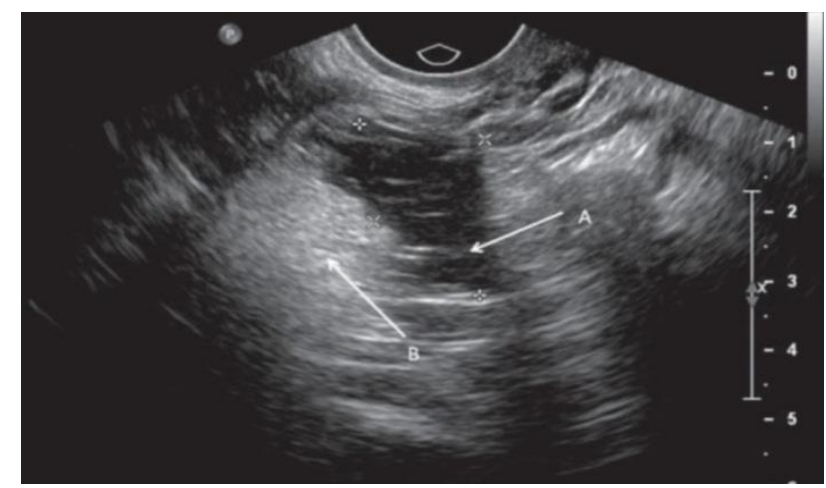

Figure 1: Ultrasonographic picture showing dot and dash appearance of the adnexal mass suggestive of dermoid cyst.

There was no other cause to which this fetal growth restriction and oligohydramnios could be attributed rather than pressure effect of the huge size teratoma located in the left adnexa. Considering normal Doppler tracings, a conservative approach was done to continue pregnancy upto 37 weeks with biweekly NST and biophysical profile in antenatal clinic. Umbilical artery Doppler showed good diastolic flow till term. At 37 weeks gestation, fetal parameters were corresponding to 32 weeks with an estimated fetal weight of $1.7 \mathrm{~kg}$. AFI gradually reduced to $4.5 \mathrm{~cm}$, although gross fetal movements and breathing movements were noted. She underwent an elective caesarean section as she was not willing for a trial of labor after caesarean.

Pre-operative hematological investigations were within normal limits. Under spinal anesthesia, abdomen was opened by a lower transverse incision. Previous scar was intact. Very minimal clear liquor was drained and a live born baby girl of $1.8 \mathrm{~kg}$ was delivered as cephalic with good Apgar scores of 9 and 10 at 1 and 5 minutes after birth respectively. Placenta and membranes were delivered in toto. Uterus was normal in morphology and was stitched in two layers. Right fallopian tube and ovary were normal. Towards the left iliac and lumbar region, a large ovarian cyst with a smooth surface was noticed. It grossly measured around $15 \times 12 \mathrm{~cm}$ and was round to ovoid in shape with 3 turns of torsion present in the tubo-ovarian segment (Figure 2). A gentle detorsion followed by enucleation and cystectomy was done after careful preservation of the fimbrial end of the left fallopian tube. There was no intraperitoneal spillage of contents from the cyst prior to removal from the abdomen. On cut section, there was presence of straw colour fluid, pultaceous material and hair thereby assuring the diagnosis of a dermoid cyst (Figure 3).

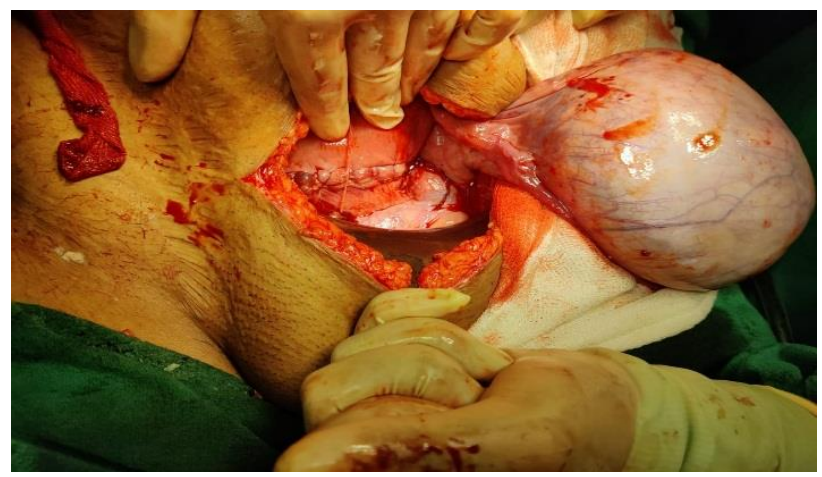

Figure 2: Intra-operative picture of the adnexal mass and the uterus.

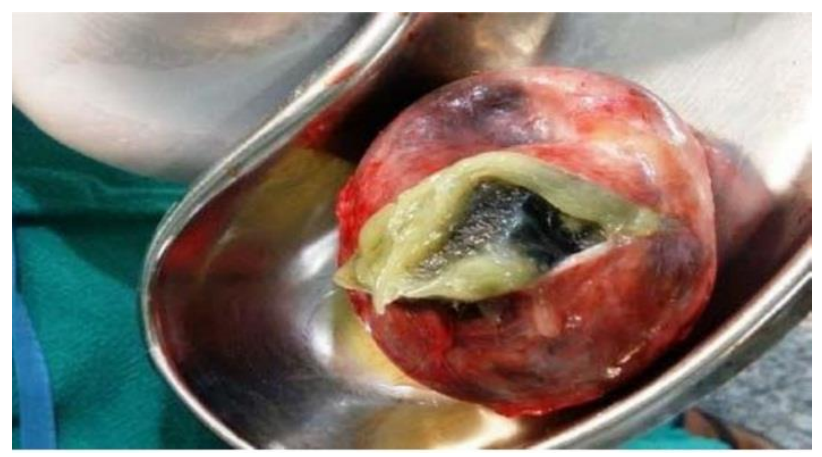

Figure 3: Cut section of the mass showing hair and gelatinous material.

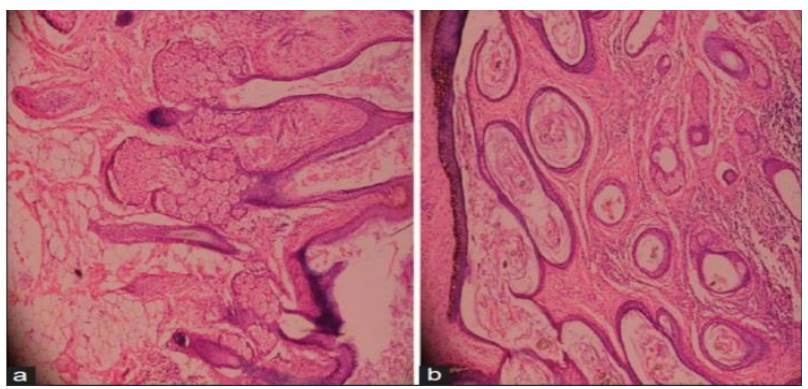

Figure 4: Microphotograph of the cyst showing stratified squamous epithelium with associated sebaceous glands suggestive of a mature cystic teratoma.

The baby was kept in neonatal intensive care unit (NICU) for 72 hours. Although initial feeds were started with expressed breastmilk via spoonfeed, baby was soon shifted to mother's side after 72 hours of observation. Exclusive breastfeeding was thereby initiated and both mother and baby were discharged under stable condition after 5 days 
of hospital stay. Microphotographic study showed that the cyst was lined by flattened squamous epithelium along with hair follicles and skin appendages. There were focal areas of cartilage and sebaceous glands (Figure 4). There was no immature component or features of atypia, thus confirming the diagnosis of a mature cystic teratoma.

Both mother and baby are doing fine at 4 weeks postdelivery and will follow-up in post-partum clinic at six weeks for examination and contraceptive counselling.

\section{DISCUSSION}

Dermoids constitute $20-40 \%$ of ovarian neoplasms in pregnancy. ${ }^{2}$ Being the most common tumor, they generally remain asymptomatic throughout pregnancy. They are mostly diagnosed during routine antenatal ultrasounds and appear as unilocular or multilocular cystic adnexal masses with mural nodules and echogenic masses with posterior sound attenuation. ${ }^{3}$ Complications in the form of torsion, infection, hemorrhage, rupture and malignant transformations are mostly seen in the second trimester of pregnancy. ${ }^{4}$ However, dermoids causing intrauterine pressure effects leading to FGR is an extremely rare phenomenon to be observed. ${ }^{5}$ Index patient presented with intrauterine growth restriction which could not be attributed to any obstetric or medical cause other than the pressure effect of the huge left ovarian dermoidcyst of $15 \times 12 \mathrm{~cm}$

Adnexal masses measuring less than $5 \mathrm{~cm}$ rarely cause symptoms. ${ }^{1}$ Ovarian masses measuring more than $5 \mathrm{~cm}$. should be followed-up with serial ultrasounds. Ideal timing to go for surgical removal of large adnexal masses is the second trimester. ${ }^{6}$ Although risk of miscarriage following surgical resection of ovarian tumor during pregnancy is roughly around $2.8 \%$, yet risk associated with torsion, hemorrhage and preterm labor can be eventually averted through timely surgical interventions in early second trimester. ${ }^{6,7}$ Unilateral simple ovarian cysts, $5-8 \mathrm{~cm}$ in size, should be evaluated sonologically upto $16-18$ weeks and if they fail to regress or increase in size, surgical intervention should be undertaken by 18 weeks. ${ }^{8}$ During pregnancy, tumor markers are not reliable to assess the risk of malignancy of ovarian masses. ${ }^{2}$ Had it not been the difficult coronavirus pandemic, diagnosis of this large size dermoid cyst would have been possible in early gestation. Timely surgical intervention would have prevented late complications like severe fetal growth restriction and oligohydramnios in this pregnancy. Such large teratomas causing FGR can be explained by extrauterine pressure effects or due to tumour deriving its blood supply from the ovarian and uterine arteries predominantly. ${ }^{5}$

\section{CONCLUSION}

Surgical intervention of large adnexal masses during the second trimester of pregnancy can avert adverse outcomes like obstructed labor, dystocia, torsion, hemorrhage and rupture of cysts. In index case, dermoid has caused FGR and oligohydramnios. Although very rare, yet such complications do occur at times. It is a time for obstetricians to serially monitor all adnexal masses in pregnancy and timely intervene so that late complications can be avoided.

Funding: No funding sources

Conflict of interest: None declared

Ethical approval: Not required

\section{REFERENCES}

1. Attia L, Chachia A, Ben TR, Bennour G, Makhlouf T, Koubaa A. Benign ovarian tumors during pregnancy. A review of 26 cases. Tunis Med. 2008;86(7):680-4.

2. Tariel O, Huissoud C, Rudigoz RC, Dubernard G. Presumed benign ovarian tumors during pregnancy. $\mathrm{J}$ Gynecol Obstet Biol Reprod. 2013;42(8):842-55.

3. Sahin H, Abdullazade S, Sanci M. Mature cystic teratoma of the ovary: a cutting edge overview on imaging features. Insights Imaging. 2017;8(2):22741.

4. Chaudhary H, Jindal A, Sharma P. Ruptured dermoid cyst during pregnancy: a rare case report. J Gynecol Women's Health. 2018;10(2):555781.

5. Das R, Rajbhandari S. An ovarian dermoid cyst in pregnancy: a rare cause of Intrauterine growth restriction. Medphoenix. 2020;5(1):75-8.

6. Testa AC, Mascilini F, Quagliozzi L, Moro F, Bolomini G, Mirandola MT, et al. Management of ovarian masses in pregnancy: patient selection for interventional treatment. Int $\mathbf{J}$ Gynecol Cancer. 2021;31(6):899-906.

7. Qublan HS, Al-Ghoweri AS, Al-Kaisi NS, AbuKhait SA. Benign mucinous cystadenoma with stromal luteinization during pregnancy: a hormonally responsive tumor and a rare cause of fetal intrauterine growth restriction. J Obstet Gynecol Res. 2002;28(4):104-7.

8. Mandi D, Mondal RC, Bhar D, Maity AK, Nandi MK, Singh K. Successful vaginal delivery despite a huge ovarian mucinous cystadenoma complicating pregnancy: A case report. Iran $\mathbf{J}$ Med Sci. 2013;38(4):339-42.

Cite this article as: Anupma, Sarkar A, Yadav D, Sharma JC. Large ovarian dermoid, a cause for fetal growth restriction and oligohydramnios: rare instance in literature. Int J Reprod Contracept Obstet Gynecol 2021;10:4328-30. 